\title{
A decade of clinical negligence in ophthalmology
} Nadeem Ali

\author{
Address: Royal Victoria Infirmary, Queen Victoria Road, Newcastle-upon-Tyne, NE1 4LP, UK \\ Email: Nadeem Ali - nadeem.ali@nhs.net
}

Published: 20 December 2007

BMC Ophthalmology 2007, 7:20 doi:10.1|86/I47|-24I5-7-20

This article is available from: http://www.biomedcentral.com/I47I-24I5/7/20

(C) 2007 Ali; licensee BioMed Central Ltd.

This is an Open Access article distributed under the terms of the Creative Commons Attribution License (http://creativecommons.org/licenses/by/2.0), which permits unrestricted use, distribution, and reproduction in any medium, provided the original work is properly cited.
Received: 2 November 2007

Accepted: 20 December 2007

\begin{abstract}
Background: To present an overview of the clinical negligence claims for ophthalmology in the National Health Service (NHS) in England from 1995 to 2006. To compare ophthalmic subspecialties with respect to claim numbers and payments.

Methods: All the claims on the NHS Litigation Authority database for ophthalmology for the period 1995 to 2006 were analysed. Claims were categorised by ophthalmic subspecialty, and subspecialties were ranked according to numbers of claims, total damages paid, average level of damages and paid:closed ratio (a measure of the likelihood of a claim resulting in payment of damages).

Results: There were 848 claims, $65 \mathrm{I}$ of which were closed. $46 \%$ of closed claims resulted in payment of damages. The total cost of damages over the period was $f I I$ million. The mean level of damages was $£ 37,100$. Cataract made up the largest share of claims (3I\%), paediatric ophthalmology had the highest mean damages $(£ \mid 70,000)$, and claims related to glaucoma were most likely to result in payment of damages (64\%).

Conclusion: Clinical negligence claims in ophthalmology in England are infrequent, but most ophthalmologists will face at least one in their career. Ophthalmic subspecialties show marked differences with regard to their litigation profiles. From a medical protection perspective, these results suggest that indemnity premiums should be tailored according to the subspecialty areas an ophthalmologist is involved in.
\end{abstract}

\section{Background}

Ophthalmic subspecialties differ significantly from each other in terms of disease conditions, demographics, treatments, and patient expectations. From a medicolegal perspective, this diversity means that ophthalmic subspecialties should be considered separately, rather than grouped together. Very little has been published in the field of ophthalmic negligence, however, which aims to compare and contrast between the clinically recognised ophthalmic subspecialties.
An ideal data source which may be used to study ophthalmic subspecialty litigation is the claims database of the National Health Service Litigation Authority (NHSLA). The NHSLA handles all claims against National Health Service (NHS) trusts in England [1]. Its database includes claims from April 1995 onwards. From 1995 to 2002, some trusts handled smaller claims by themselves, but the NHSLA estimates that over $90 \%$ of claims in that period reached the database (personal communication). Since April 2002, the NHSLA handled every clinical negligence claim in the NHS, and so the database from that date is all-inclusive. 
Although there have been reports about ophthalmic litigation in USA, data from a European perspective are generally lacking [2]. Previous UK studies which analysed claims in the private sector represent a different spectrum of practice from the mainstream NHS [3,4]. Studies which have utilised NHSLA data for ophthalmology have been confined to a single subspecialty $[5,6]$. Furthermore, there are very few reports at all which seek to compare between ophthalmic subspecialties. Those that did, have utilised classifications that do not correspond to the ophthalmic subspecialties found in clinical practice [7]. Drawing on the NHSLA database, this study aims to provide a decadelong overview of ophthalmology negligence claims in the NHS in England, focusing on comparisons between the standard ophthalmic subspecialties.

\section{Methods}

Data on ophthalmology-related claims in the NHS were obtained by submitting an online data request form to the NHSLA. Information was requested on all claims arising from the specialty of ophthalmology from 1995 to 2006 . The anonymised, tabulated summary data provided by the NHSLA were then analysed and claims were grouped according to the following ophthalmic subspecialty divisions: cataract, cornea (including external eye disease), oculoplastics (including lacrimal and orbital), uveitis, glaucoma, vitreo-retinal (VR) surgery, medical retina, neuro-ophthalmology, strabismus, paediatric ophthalmology (paediatrics), oncology, and trauma. There was also a miscellaneous category for claims where a subspecialty could not be determined, as well as claims unrelated to a subspecialty (eg falls in the department).

For the whole ophthalmology data set, and for each ophthalmic subspecialty, the number of ongoing claims (open), completed claims (closed), and claims with payment of damages (paid) were determined. The total and mean level of damages, as well as the paid:closed ratio (which indicates the likelihood of a claim resulting in payment of damages) were calculated for each ophthalmic subspecialty. Subspecialties were ranked according to number of claims, total damages, mean level of damages and paid:closed ratio.

In line with NHSLA guidance, the completed study was submitted to a Risk Manager at the NHSLA for approval and comments.

\section{Results}

The total number of claims from ophthalmology in the NHS in England for the period April 1995 to August 2006 was 848 . This implies a mean annual incidence of around 75 claims per year. Over the same period, the total number of claims handled by the NHSLA for all specialties was 34,497 , of which 13,449 were from surgical spe- cialties [8]. Ophthalmology claims thus accounted for around $2.5 \%$ of the total number of claims, and $6.3 \%$ of the surgery claims over this period.

Of the 848 claims from ophthalmology, 651 were closed and 197 remained open. Of the 651 closed claims, 299 resulted in payments, giving a paid:closed ratio of $46 \%$. The total damages for the 299 paid claims were $£ 11.1$ million over the whole period, or $£ 982,000$ per year. The mean damages for a paid claim was $£ 37,100$.

\section{Numbers of claims}

In Table 1, the ophthalmic subspecialties are ranked by numbers of claims. Cataract accounts for nearly a third of claim numbers, with retinal specialties (VR and medical retina) comprising the next largest grouping.

\section{Total damages}

In Table 2, the ophthalmic subspecialties are ranked by total damages. Five subspecialties (cataract, glaucoma, medical retina, paediatrics and neuro-ophthalmology) together account for $69 \%$ of the total damages for the specialty. The lowest ranking five specialties, however, (strabismus, oncology, trauma, cornea and oculoplastics) are responsible for only $8 \%$ of the total damages.

\section{Mean level of damages paid}

In Table 3, the ophthalmic subspecialties are ranked by mean level of damages (in paid cases). Paediatric ophthalmology has a level of mean damages over twice that of any other subspecialty. Cataract claims, though frequent, do not result in high payments.

\section{Paid:closed ratio}

In Table 4, the ophthalmic subspecialties are ranked by the paid:closed ratio, a measure of the likelihood of a claim resulting in payment of damages. There is a more

Table I: Ophthalmic subspecialties ranked by numbers of claims

\begin{tabular}{lcc}
\hline Subspecialty & Number of claims & $\%$ of total \\
\hline Cataract & 264 & $31 \%$ \\
VR & 81 & $10 \%$ \\
Medical retina & 64 & $8 \%$ \\
Cornea & 53 & $6 \%$ \\
Glaucoma & 43 & $5 \%$ \\
Oculoplastics & 42 & $5 \%$ \\
Neuro-ophthalmology & 40 & $5 \%$ \\
Paediatrics & 33 & $4 \%$ \\
Trauma & 32 & $4 \%$ \\
Uveitis & 28 & $3 \%$ \\
Strabismus & 23 & $3 \%$ \\
Oncology & 9 & $1 \%$ \\
Miscellaneous & & $16 \%$ \\
\hline
\end{tabular}


Table 2: Ophthalmic subspecialties ranked by total damages

\begin{tabular}{lcc}
\hline Subspecialty & Total damages $(\ell)$ & $\%$ of total \\
\hline Cataract & 1.9 million & $17 \%$ \\
Glaucoma & 1.8 million & $16 \%$ \\
Medical retina & 1.6 million & $14 \%$ \\
Paediatrics & 1.4 million & $12 \%$ \\
Neuro-ophthalmology & 1.1 million & $10 \%$ \\
VR & 750,000 & $7 \%$ \\
Uveitis & 540,000 & $5 \%$ \\
Oculoplastics & 350,000 & $3 \%$ \\
Cornea & 270,000 & $2 \%$ \\
Trauma & 190,000 & $2 \%$ \\
Oncology & 140,000 & $1 \%$ \\
Strabismus & 20,000 & $0.1 \%$ \\
Miscellaneous & & $10 \%$ \\
\hline
\end{tabular}

even distribution among subspecialties for this parameter than for claim numbers, total damages, or mean level of damages.

\section{Discussion}

This study provides an overview of clinical negligence claims in ophthalmology in England from 1995 to 2006 within the NHS. The main findings of this study can be summarised as follows. In the context of NHS litigation as a whole, ophthalmology accounts for only $2.5 \%$ of the total number of clinical negligence claims. The total cost to the NHS of damages for ophthalmology claims was $£ 11$ million in the last decade. Cataract accounts for nearly a third of ophthalmology claims, with retinal subspecialties making up nearly $20 \%$. In terms of total damages paid, however, cataract is only slightly greater than glaucoma, medical retina, paediatrics and neuro-ophthalmology. Paediatrics has the highest level of damages, over twice

Table 3: Ophthalmic subspecialties ranked by mean level of damages

\begin{tabular}{lc}
\hline Subspecialty & Mean damages $(t)$ \\
\hline Paediatrics & 170,000 \\
Glaucoma & 77,000 \\
Uveitis & 68,000 \\
Neuro-ophthalmology & 63,000 \\
Medical retina & 57,000 \\
Oncology & 47,000 \\
VR & 27,000 \\
Cataract & 20,000 \\
Oculoplastics & 20,000 \\
Trauma & 19,000 \\
Cornea & 13,000 \\
Strabismus & 10,000 \\
& \\
Miscellaneous & 29,000 \\
\hline
\end{tabular}

Table 4: Ophthalmic subspecialties ranked by the paid:closed ratio

\begin{tabular}{lc}
\hline Subspecialty & Paid:closed ratio \\
\hline Glaucoma & $64 \%$ \\
Neuro-ophthalmology & $58 \%$ \\
Oculoplastics & $58 \%$ \\
Medical retina & $52 \%$ \\
Cornea & $50 \%$ \\
Paediatrics & $47 \%$ \\
Cataract & $46 \%$ \\
Trauma & $45 \%$ \\
VR & $40 \%$ \\
Uveitis & $33 \%$ \\
Oncology & $33 \%$ \\
Strabismus & $25 \%$ \\
Miscellaneous & \\
\end{tabular}

that for every other subspecialty. Cataract damages, although frequent, are less costly than the average for the specialty. The likelihood of a claim resulting is payment of damages is highest for glaucoma, followed by neuro-ophthalmology and oculoplastics.

The principal strength of the study is that the NHSLA data are prospective and virtually comprehensive. This is because all claims in the NHS in England are, as a matter of procedure, handled by the NHSLA. The main limitation of the data is the brevity of the case descriptions supplied, which limits detailed analysis of causative factors for each claim. This also accounts for a large proportion of the claims which were classified in the miscellaneous category. Further limitations are that the data do not include claims from outside the NHS (ie private practice and general practice), and are confined to England.

From a risk management perspective, it is important to highlight that the negligence claims discussed in this study represent just the tip of the risk iceberg. Nearmisses, undetected adverse outcomes, cases in which patients do not take matters further, and resolution of complaints by local or national non-legal bodies represent a large pool of clinical incidents, most of which never reach the NHSLA.

Most of the reports about ophthalmic litigation in the literature come from USA. These include the publications of large medical insurance groups such as the Ophthalmic Mutual Insurance Company (OMIC) and the Physicians Insurance Association of America (PIAA). The PIAA is an association of over 50 medical malpractice insurance companies, which between them insure over $60 \%$ of private practitioners in USA. The PIAA's summary data of claims for ophthalmology from 1985-2005 [9] provide a useful point of comparison with the NHSLA data. The rel- 
ative contribution of ophthalmology to medical litigation is remarkably similar in England and USA (NHSLA: 2.5\% of total claims; PIAA: $2.9 \%$ ). The average level of damages awarded, though, is much higher in USA (PIAA: $\$ 174,000$; NHSLA: $£ 37,100)$. The proportion of claims resulting in payment (the paid:closed ratio), however, is higher in England (NHSLA: 46\%; PIAA 29\%).

Comparisons of claims between ophthalmic subspecialties in the literature are much less complete than the present study, and have used categorisations more of interest to insurers than to doctors [7]. Certain points of agreement, however, can be realised. Due to its high volume, cataract is consistently found to be the largest single contributor to claim numbers, accounting for $31 \%$ of the NHSLA claims. Cataract accounted for $47 \%$ of the PIAA claims and $29 \%$ of an older series from New Jersey [10]. In a personal review of 700 medicolegal cases, cataract was the most frequent (22\% of total) [7]. A recent review of claims in the private sector in the UK also found cataract to be the commonest reason for claims, making up $39 \%$ of the total [4]. The finding that paediatric ophthalmology claims result in the highest levels of payment is corroborated by a study which examined only high-payout cases in USA [11]. This reported that patients aged under ten years had the largest monetary awards. The finding that glaucoma has the highest paid:closed ratio (64\%) is confirmed by the PIAA data (42\%). An area of ophthalmic practice conspicuously absent from the NHSLA data is laser refractive surgery, which is scarcely performed in the NHS. This is a major contributor to litigation in private practice, however $[2,4]$.

In 2005, there were 2,327 medical staff in ophthalmology in England, of which 820 were consultants [12]. Using the annual claim incidence reported above, and with certain assumptions to permit estimation, the chance of an ophthalmologist of any grade being subjected to a claim in a ten-year period is approximately $30 \%$. The average doctor in ophthalmology would therefore face one claim in a thirty year career. For a consultant, there is a $90 \%$ chance of having a claim in ten years arising from a patient under his care, which equates to two claims in a twenty year career as a consultant. Claims may be infrequent on a national level, but the majority of ophthalmologists in England will face at least one claim in their NHS career. Of some comfort is the fact that most claims never reach the courtroom, with $38 \%$ being abandoned by the claimant and a further $43 \%$ settled out of court [8].

\section{Conclusion}

Clinical negligence claims in ophthalmology in England are reassuringly infrequent, but most ophthalmologists will face at least one in their career. Ophthalmic subspecialties show marked differences with regard to their liti- gation profiles. Cataract has the most claims, paediatric ophthalmology the highest level of damages, and glaucoma the highest rate of claim success. From a medical protection perspective, these results suggest that indemnity premiums should be tailored according to the subspecialty areas an ophthalmologist is involved in.

\section{Competing interests}

The author(s) declare that they have no competing interests.

\section{Authors' contributions}

NA devised and conducted the study, and wrote the paper.

\section{Acknowledgements}

The author wishes to acknowledge the assistance of Ruth Symons, Risk Manager, NHSLA who supplied the raw data and reviewed the paper, and Lori Smarr, Director of Loss Prevention and Research at the Physicians Insurance Association of America, who clarified aspects of the PIAA data.

\section{References}

I. NHS Litigation Authority: Factsheet I: Background Information. 2005.

2. Mavroforou A, Michalodimitrakis E: Physicians' liability in ophthalmology practice. Acta Ophthalmol Scand 2003, 81:32I-325.

3. Bhan A, Dave D, Vernon SA, Bhan K, Bhargava J, Goodwin H, Medical Defence Union; Medical Protection Society; Medical and Dental Defence Union of Scotland: Risk management strategies following analysis of cataract negligence claims. Eye 2005, 19:264-268.

4. Tomkins C: Over $\mathbf{I} 20$ years of defending ophthalmologists. $\mathrm{Br}$ J Ophthal 2006, 90:1084-5.

5. Ali MN, Fraser SG: Medicolegal aspects of glaucoma. Clin Risk 2007, I3:12-16.

6. Featherstone T: Risk management, adverse events and litigation in vitreoretinal surgery. Clin Risk 2007, I3:7- II.

7. Bettman JW: Seven hundred medicolegal cases in ophthalmology. Ophthalmology 1990, 97:1379-1384.

8. NHS Litigation Authority: Factsheet 3: Information on claims. 2006.

9. Physician Insurers Association of America (PIAA): Risk Management Review - Ophthalmology. 2005.

10. Krausher MF, Turner MF: Medical malpractice litigation in ophthalmology: the New Jersey Experience. Ophthalmic Surg 1986, | 7:67|-674.

II. Kraushar MF, Robb JH: Ophthalmic malpractice lawsuits with large monetary awards. Arch Ophthalmol 1996, I | 4:333-337.

12. The Information Centre: NHS Hospital and Community Health Services Medical and Dental Workforce Census: England: 30 September 2005. [http://www.ic.nhs.uk/pubs/nhsstaff/mddetailre spdf/file]. accessed 28 November 2007

\section{Pre-publication history}

The pre-publication history for this paper can be accessed here:

http://www.biomedcentral.com/1471-2415/7/20/prepub 